\title{
Argila e matéria orgânica e seus efeitos na agregação em diferentes usos do solo
}

\author{
Clay and organic matter and effects on aggregation in different soil uses
}

\author{
Antonio Sousa Silva Ivandro de França da Silva ${ }^{\text {II }}$ Lucas Borchartt Bandeira III \\ Bruno de Oliveira Dias ${ }^{I I}$ Luís de França da Silva Neto ${ }^{\text {IV }}$
}

\section{RESUMO}

\begin{abstract}
Mudanças no uso do solo afetam a quantidade de argila e matéria orgânica do solo (MOS) e estes, por sua vez, afetam a agregação. Avaliou-se como diferentes usos afetaram a agregação de um Argissolo na microrregião do Brejo Paraibano. Foram avaliadas três áreas contíguas com declive fortemente ondulado, sendo uma mata nativa, um plantio de sabiá (Mimosa caesalpiniaefolia) e uma pastagem com brachiaria (Brachiaria decumbens). Foram coletadas amostras de solo para determinação da textura, macro e microagregados secos (Macro-s e Micro-s) e úmidos (Macro-u e Micro-u), diâmetro médio ponderado de agregados secos (DMPA-s) e úmidos (DMPA-u), índice de estabilidade de agregados (IEA), teores de MOS e seu fracionamento em ácido fúlvico (AF), ácido húmico (AH) e humina (HUM), em quatro profundidades: $0,0-2,5 \mathrm{~cm}$, 2,5-5,0 cm, 5,0-10,0 cm e 10,0-20,0 cm. Pôde-se notar que as quantidades de argila, MOS, HUM, Macro-s, Macro-u, DMPA-s, DMPA-u e IEA, são sempre maiores na área de mata nativa, em todas as profundidades. O plantio de sabiá apresentou maiores teores de AH e menores quantidades de Macro-u nas duas últimas profundidades em relação ao pasto. A HUM apresentou melhor correlação com a agregação do solo. Mudanças no uso causaram degradação do solo na microrregião do Brejo Paraibano.
\end{abstract}

Palavras-chave: mata mativa, pastagem, Mimosa caesalpiniaefolia.

\section{ABSTRACT}

Changes in soil use affect the amount of clay and soil organic matter (SOM) and these, in turn, affect the aggregation. It was evaluated how different uses affect the aggregation of the microregion of Brejo Paraibano. Three adjacent areas were evaluated with strongly wavy slope, being one of them native forest, and the other ones a cultivation of sabiá (Mimosa caesalpiniaefolia) and a pasture of brachiaria (Brachiaria decumbens). Soil samples were collected for determination of texture, macro and dry microaggregates (Macro-s e Micro-s) and humid (Macro-u e Micro- $u$ ), mean weight diameter of dry aggregates (DMPA-s) and humid (DMPA-u), index of aggregate stability (IEA), contents of SOM and its fractionation in fulvic acid (FA), humic acid (HA) and humin (HUM) at four depths: $0.0-2.5 \mathrm{~cm}, 2.5-5.0 \mathrm{~cm}, 5.0-10.0 \mathrm{~cm}$ and 10.0-20.0 cm. It was observed that the amount of clay, SOM, HUM, Macro-s, Macro-u, DMPA-s, DMPA-u and IEA are always higher in native forest, at all depths. The cultivation of sabiá has presented higher contents of HA fraction and smaller amounts of Macro-u past two depths in relation to pasture. The HUM has shown better correlation with soil aggregation. Changes in the soil use have caused soil degradation in the microrregion of Brejo Paraibano.

Key words: native forest, pasture, Mimosa caesalpiniaefolia.

\section{INTRODUÇÃO}

A estrutura do solo resulta da formação dos agregados e pode ser avaliada quantitativamente pela distribuição dos agregados estáveis em água sob diferentes diâmetros de peneiras (SILVA \& MIELNICZUK, 1997; VEZZANI \& MIELNICZUK, 2011). Para SILVA \& MIELNICZUK (1997), a qualidade da agregação do solo pode ser determinada pelo diâmetro médio ponderado de agregados (DMPA), quando os agregados são relacionados por classes de diâmetro, sendo que, quanto mais agregados

Instituto Federal Baiano, Campus Senhor do Bonfim, 48970-000, Senhor do Bonfim, BA, Brasil. E-mail: sousaaantonio@ bol.com.br. Autor para correspondência.

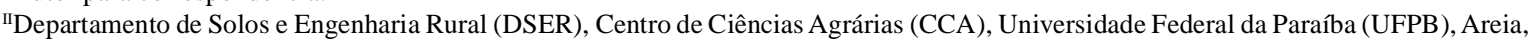
PB, Brasil.

IIIInstituto Federal da Paraíba, João Pessoa, PB, Brasil.

${ }^{\mathrm{IV}}$ Embrapa Solos, Rio de Janeiro, RJ, Brasil. 
se fragmentarem em água, menor a sua estabilidade. Segundo PORTUGAL et al. (2010), mudanças no uso do solo para sistemas com maior revolvimento afetam a agregação, resultando em degradação.

A matéria orgânica exerce grande influência no processo de formação e estabilização dos agregados (VEZZANI \& MIELNICZUK, 2011; SILVA \& MIELNICZUK; 1997). Há estudos que destacam a correlação entre os teores de matéria orgânica e a dinâmica dos agregados dos solos. Os trabalhos realizados por FONTANA et al. (2010) e PORTUGAL et al. (2010) mostraram que a relação da matéria orgânica com a agregação do solo pode ser avaliada por meio das substâncias húmicas, que são importantes no processo de formação e estabilização, devido sua ação cimentante, que possibilita a formação de agregados estáveis. Entre elas, a humina se destaca, pois tem efeito benéfico na estabilidade dos agregados.

Além disso, textura do solo afeta a estabilidade e a própria formação de agregados, e solos com maior teor de argila favorecem a agregação. Segundo VEZZANI \& MIELNICZUK (2011), a maior presença de argila contribuiu para aumentar a aproximação das partículas do solo. Por outro lado, horizontes arenosos dificultam a proteção física da matéria orgânica, dificultando a formação de agregados (SANTOS et al., 2011).

No Brejo Paraibano, os solos apresentam declividade fortemente ondulada e vêm sendo cultivado de forma intensiva com pastagens em substituição à cana-de-açúcar, o que tem levando a degradação de suas propriedades físicas (SOUZA, 2010; SANTOS et al., 2010). Com a substituição das pastagens por sabiá (Mimosa caesalpiniaefolia), planta arbustiva e lenhosa, usada para produção de estacas no Brejo Paraibano, os solos tem recebido uma maior proteção, devido à elevada deposição de serapilheira (FERREIRA et al., 2007).

Este trabalho objetivou avaliar como as mudanças no uso do solo afetaram os teores de argila, matéria orgânica do solo (MOS) e suas frações e como estes influenciaram a agregação em áreas de elevada declividade sob diferentes coberturas vegetais na microrregião do Brejo Paraibano.

\section{MATERIAL E MÉTODOS}

O experimento foi conduzido na Fazenda Morada Nova, município de Areia-PB, a $5 \mathrm{~km}$ da cidade. A maior parte da área da fazenda é utilizada com pastagens. O pasto foi implantado há 15 anos em substituição à exploração por décadas com cana-deaçúcar, que era sempre queimada antes do corte. Há 7 anos, uma parte desse pasto foi substituído pelo plantio de sabiá, planta arbustiva e lenhosa, no espaçamento de $1 \times 1 \mathrm{~m}$. Para o plantio das mudas de sabiá, o solo foi revolvido manualmente com uso de enxadas. O solo da referida fazenda nunca recebeu a aplicação de adubos ou corretivos. Existe ao lado dessas explorações uma mata nativa secundária em desenvolvimento desde os anos de 1950, que serviu como comparativo. O solo local foi classificado por BRASIL (1972) como PODZÓLICO VERMELHO AMARELO, que na classificação de EMBRAPA (2006) passa a ser Argissolo Vermelho-Amarelo. O clima é do tipo As' de Köppen (quente e úmido, com chuvas no período de março a julho). Nas áreas estudadas, com um clinômetro, foi determinada a declividade, obtendo-se sob mata declividade média de $30 \%$, sob sabiá $20 \%$ e sob pasto $25 \%$, classificando essas áreas em função do declive como forte ondulada (BRASIL, 1972).

Os tratamentos utilizados foram representados por três sistemas de uso: mata nativa secundária, cultivode sabiá(Mimosacaesalpiniaefolia) e pastagem com brachiaria (Brachiaria decumbens). A área avaliada foi de um hectare em cada sistema, nos quais se coletaram amostras de solo para determinação da textura, macroagregados e microagregados secos (Macro-s e Micro-s) e úmidos (Macro-u e Micro-u), diâmetro médio ponderado de agregados secos (DMPA-s) e úmidos (DMPA-u) e o índice de estabilidade de agregados (IEA). Determinaramse também os teores de matéria orgânica do solo (MOS) e efetuou-se fracionamento nas frações ácido fúlvico (AF), ácido húmico (AH) e humina (HUM), em quatro profundidades do solo: $0,0-2,5 \mathrm{~cm}, 2,5-$ $5,0 \mathrm{~cm}, 5,0-10,0 \mathrm{~cm}$ e $10,0-20,0 \mathrm{~cm}$. As amostras de solo foram coletadas, em três posições de declividade: parte superior, mediana e inferior, seguindo uma linha em curva de nível. Em cada linha de declive foram coletados solos em três diferentes pontos, em quatro profundidades, perfazendo um total de 108 amostras, sendo 36 por área, para análises de agregados. Para o fracionamento da MOS, em cada linha, fez-se uma amostra composta, em suas respectivas profundidades, num total de 36 amostras, sendo 12 por área.

As análises de agregados do solo foram processadas no Laboratório de Física do solo do Departamento de Solos e Engenharia Rural (DSER) do Centro de Ciências Agrárias (CCA) da UFPB. A separação dos agregados secos e a determinação do DMPAs foram realizadas utilizando-se amostras com aproximadamente $50 \mathrm{~g}$ de agregados com diâmetro inferior a $9,52 \mathrm{~mm}$, passadas em peneiras de 2,00; 1,$00 ; 0,50 ; 0,25 ; 0,106$ e $0,053 \mathrm{~mm}$ de malha em um vibrador Produtest, durante um minuto (SILVA \& 
MIELNICZUK, 1997). A separação por via úmida e a determinação do DMPAu, seguiu a metodologia de TISDALL et al. (1978), modificado por CARPENEDO \& MIELNICZUK (1990). O índice IEA foi obtido através da relação entre o DMPAu/ DMPAs (SILVA \& MIELNICZUK, 1997). A análise da granulometria foi realizada segundo metodologia descrita em EMBRAPA (1997).

A análise da MOS foi realizada no Laboratório de Química e Fertilidade do Solo, do DSER/CCA/UFPB conforme metodologia descrita em EMBRAPA (1997). O fracionamento da MOS nas fações AF, AH e HUM foi feito em triplicata, seguindo a metodologia de BENITES et al. (2003). Neste caso, as amostras foram passadas em peneiras de 0,053 $\mathrm{mm}$. Em amostras de $4 \mathrm{~g}$ adicionaram-se 40 $\mathrm{ml} \mathrm{NaOH} \mathrm{0,1} \mathrm{mol} \mathrm{L} \mathrm{m}^{-1}$. Depois de centrifugado a 2500 rpm por 15 minutos, o sobrenadante (extrato alcalino $-\mathrm{AF}+\mathrm{AH}$ ) foi separado e o precipitado foi usado para extração do $\mathrm{C}$ associado à fração HUM. Ajustou-se o pH do extrato alcalino para 1,5 com adição de $\mathrm{H}_{2} \mathrm{SO}_{4}$. Depois de 12 horas, o AH decantou e foi separada do AF para análise do teor de $\mathrm{C}$.

$\mathrm{O}$ experimento foi analisado num esquema fatorial inteiramente casualisado, com parcelas repetidas no espaço. Quando houve diferenças entre os tratamentos, as médias foram comparadas pelo teste de Tukey a $5 \%$ de probabilidade. Utilizou-se o procedimento MIXED, para medidas repetidas, do programa SAS. Para correlação, também se usou o SAS.

\section{RESULTADOS E DISCUSSÃO}

Na tabela 1, a análise textural mostra que área sob mata possui o dobro de argila em relação à área sob sabiá e pasto. Segundo SOUZA (2010), a erosão nas áreas com elevada declividade, no Brejo Paraibano, promovem a perda de solo, principalmente de argila. Isto se deve à menor proteção oferecida ao solo nas áreas sob pasto e sob sabiá. Em todas as áreas, os teores de argila são maiores nas camadas mais profundas do solo, devido a estarem menos sujeitas à erosão e a sua proximidade do horizonte B. Devido à elevada declividade das áreas o processo erosivo é favorecido, fazendo com que o teor de argila nas áreas sob sabiá e pasto diminuir em $51 \%$ e 58\%, respectivamente, em relação à mata. De acordo com SOUZA (2010), estes resultados são esperados, uma vez que a mata oferece maior proteção ao solo contra os processos erosivos. Por outro lado, a atividade das argilas (Ta) é bem semelhante entre as áreas, onde, na primeira camada, devido aos teores de matéria orgânica, os valores são mais elevados, caindo consideravelmente nas últimas camadas.

Os maiores teores de MOS são observados na área de mata, em todas as profundidades. Embora a área de sabiá comece a aumentar os teores de MOS na superfície, ainda não difere do pasto, provavelmente devido ao pouco tempo de implantação (7 anos). O pastejo contínuo tem contribuído para os menores valores de MOS nessa área, devido ao menor aporte

Tabela 1 - Análise granulométrica, atividade das argilas (Ta), MOS e seu fracionamento nas frações ácido fúlvico (AF), ácido húmico (AH) e humina (HUM) sob área de mata, sabiá e pasto em diferentes profundidades do solo.

\begin{tabular}{|c|c|c|c|c|c|c|c|c|c|}
\hline Área & $\begin{array}{c}\text { Prof. } \\
\mathrm{cm}\end{array}$ & Areia & $\begin{array}{r}\text { Silte } \\
\mathrm{g} \mathrm{kg}^{-1} \\
\end{array}$ & Argila & $\begin{array}{l}\mathrm{Ta} \\
\mathrm{cmol}_{\mathrm{c}}\end{array}$ & $\begin{array}{l}\text { MOS } \\
\mathrm{g} \mathrm{dm}^{-3}\end{array}$ & AF & $\begin{array}{c}\mathrm{AH} \\
---\mathrm{g} \mathrm{kg}^{-1}-- \\
\end{array}$ & HUM \\
\hline \multirow{4}{*}{ Mata } & $0,0-2,5$ & 516 & 105 & 379 & 35,3 & 75,5 aA & $0,68 \mathrm{aA}$ & $3,00 \mathrm{aA}$ & 8,61 aA \\
\hline & $2,5-5,0$ & 474 & 116 & 410 & 30,4 & $66,0 \mathrm{bA}$ & $0,57 \mathrm{aA}$ & $2,78 \mathrm{aA}$ & $6,96 \mathrm{bA}$ \\
\hline & $5,0-10,0$ & 412 & 107 & 481 & 23,6 & $54,7 \mathrm{cA}$ & $0,54 \mathrm{aA}$ & $2,14 \mathrm{bA}$ & $6,52 \mathrm{bA}$ \\
\hline & $10,0-20,0$ & 408 & 155 & 437 & 24,2 & $45,7 \mathrm{cA}$ & $0,42 \mathrm{aA}$ & $1,98 \mathrm{bA}$ & $4,89 \mathrm{cA}$ \\
\hline \multirow{4}{*}{ Sabiá } & $0,0-2,5$ & 736 & 95 & 169 & 44,3 & $38,1 \quad \mathrm{aB}$ & $0,35 \mathrm{aB}$ & 2,43 aA & 3,48 aB \\
\hline & $2,5-5,0$ & 672 & 125 & 203 & 34,2 & $31,0 \mathrm{abB}$ & $0,41 \mathrm{aA}$ & $1,89 \mathrm{bA}$ & $2,59 \mathrm{abB}$ \\
\hline & $5,0-10,0$ & 629 & 114 & 257 & 23,2 & 22,3 bB & $0,32 \mathrm{aA}$ & 1,77 bA & $2,05 \mathrm{abB}$ \\
\hline & $10,0-20,0$ & 674 & 110 & 216 & 25,8 & 20,0 bB & $0,35 \mathrm{aA}$ & $1,66 \mathrm{bA}$ & $1,24 \mathrm{bB}$ \\
\hline \multirow{4}{*}{ Pasto } & $0,0-2,5$ & 771 & 83 & 146 & 31,9 & $23,1 \mathrm{aB}$ & $0,59 \mathrm{aAB}$ & $0,57 \mathrm{aB}$ & $2,29 \mathrm{aB}$ \\
\hline & $2,5-5,0$ & 717 & 113 & 170 & 26,5 & $22,7 \mathrm{aB}$ & $0,55 \mathrm{aA}$ & $0,45 \mathrm{aB}$ & $1,51 \mathrm{abB}$ \\
\hline & $5,0-10,0$ & 709 & 100 & 191 & 24,2 & $20,3 \mathrm{aB}$ & $0,48 \mathrm{aA}$ & $0,56 \mathrm{aB}$ & $1,15 \mathrm{abB}$ \\
\hline & $10,0-20,0$ & 691 & 99 & 210 & 21,8 & $19,1 \mathrm{aB}$ & $0,56 \mathrm{aA}$ & $0,53 \mathrm{aB}$ & $0,65 \mathrm{bB}$ \\
\hline
\end{tabular}

Letras minúsculas iguais em cada área na coluna e maiúsculas entre as áreas, nas respectivas profundidades, não diferem estatisticamente em nível de 5\% de probabilidade pelo teste de Tukey. 
de resíduos. PORTUGAL et al. (2008) perceberam que a mata secundária apresentava maiores teores de MOS em relação à pastagem. Para LOSS et al. (2006), os maiores teores de MOS na vegetação nativa são decorrentes do maior aporte de serrapilheira. Com exceção do pasto, observam-se acúmulo significativos de MOS na superfície das áreas estudadas. LOSS et al. (2006), PORTUGAL et al. (2008) e PULROLNIK et al. (2009) encontraram maior acúmulo de MOS em superfície devido à deposição de resíduos vegetais. A diferença, entre a primeira e última camada, foi de $44 \%, 47 \%$ e $17 \%$ para as áreas de mata, sabiá e pasto, respectivamente. A quantidade de MOS no pasto não difere em profundidade, o que pode indicar perdas elevadas, seja pela pequena deposição ou maior erosão.

Quanto ao fracionamento da MOS, a fração AF, em geral, não sofre alteração entre as áreas e profundidades devido a sua elevada mobilidade no solo, facilitando sua lixiviação; este fato é comprovado em outras pesquisas. (LOSS et al., 2006; PORTUGAL et al., 2008). Por outro lado, as frações AH e HUM apresentam altos teores na superfície e baixos valores em profundidade. As pesquisas mostram pequena mobilidade dessas frações, o que explica esse comportamento (LOSS et al., 2006; DOBBSS et al., 2009; PORTUGAL et al., 2008).

Os teores de AH são semelhantes nas áreas de mata e sabiá, e seus teores são estatisticamente maiores do que no pasto. LOSS et al. (2006) também encontraram menores teores de $\mathrm{AH}$ na área de pasto.
DOBBSS et al. (2009) notaram que os teores dessa fração acompanham os teores de matéria orgânica no solo, e, na presente pesquisa, são maiores na mata e no sabiá. Em profundidade, o AH sofre uma diminuição significativa nas áreas de mata e sabiá, o que não ocorre na área de pasto. PORTUGAL et al. (2008) e LOSS et al. (2006) observaram resultados semelhantes em profundidade nos teores do AH e atribuíram esses resultados aos maiores teores de MOS em superfície na área de mata.

Os teores de HUM são significativamente maiores na área sob mata e semelhantes na área sob sabiá e sob pasto, em todas as profundidades. Como a fração HUM é a que apresenta maior grau de estabilidade do C no solo, a constante perturbação do solo pelo pisoteio e pastoreio, e o revolvimento do solo para o plantio do sabiá, há pouco tempo, contribuíram para que as áreas sob pasto e sabiá apresentassem menores teores de $\mathrm{C}$ na fração mais estável no solo (LOSS et al., 2006; DOBBSS et al., 2009). Entre as frações estudadas, os maiores teores são da HUM, em todas as áreas e profundidades, devido a sua maior persistência no solo, tendo em vista sua dificuldade de degradação. Estes resultados estão de acordo com pesquisas realizadas nos trópicos, que se caracterizam pela concentração dessa fração (PULROLNIK et al., 2009; PORTUGAL et al., 2008).

Os Macro-s são significativamente maiores na área de mata em todas as profundidades (Tabela 2), à exceção da profundidade $10,0-20,0 \mathrm{~cm}$ na área de pasto, devido provavelmente à ação do cultivo da

Tabela 2 - Macro e microagregados secos (Macro-s e Micro-s) e úmidos (Macro-u e Micro-u), diâmetro médio ponderado de agregados secos (DMPA-s) e úmidos (DMPA-u) e o índice de estabilidade de agregados (IEA) sob área de mata, sabiá e pasto em diferentes profundidades do solo.

\begin{tabular}{|c|c|c|c|c|c|c|c|c|}
\hline Área & $\begin{array}{c}\text { Prof. } \\
\mathrm{cm}\end{array}$ & Macro-s & Micro-s & Macro-u & Micro-u & DMPA-S & $\begin{array}{l}\text { DMPA-u } \\
\text { m -------.- }\end{array}$ & IEA \\
\hline \multirow{4}{*}{ Mata } & $0,0-2,5$ & $97,9 \mathrm{aA}$ & $2,1 \mathrm{a} \mathrm{B}$ & $96,7 \mathrm{aA}$ & $3,3 \mathrm{aB}$ & $3,91 \mathrm{aA}$ & 3,83 bA & $0,98 \mathrm{aA}$ \\
\hline & $2,5-5,0$ & $98,1 \mathrm{aA}$ & 1,9 a $\mathrm{B}$ & $96,8 \mathrm{aA}$ & $3,2 \mathrm{aB}$ & $4,29 \mathrm{aA}$ & $4,16 \mathrm{abA}$ & $0,97 \mathrm{aA}$ \\
\hline & $5,0-10,0$ & $97,7 \mathrm{aA}$ & 2,3 a $\mathrm{B}$ & $96,1 \mathrm{aA}$ & 3,9 a C & $4,32 \mathrm{aA}$ & 4,23 a $\mathrm{A}$ & $0,98 \mathrm{aA}$ \\
\hline & $10,0-20,0$ & $97,2 \mathrm{aA}$ & 2,8 a B & $94,9 \mathrm{aA}$ & 5,1 a C & $4,44 \mathrm{aA}$ & 4,28 a A & $0,96 \mathrm{aA}$ \\
\hline \multirow{4}{*}{ Sabiá } & $0,0-2,5$ & $94,3 \mathrm{aB}$ & $5,7 \mathrm{aA}$ & $77,1 \mathrm{aB}$ & $22,9 \mathrm{bA}$ & $2,74 \mathrm{aB}$ & $1,44 \mathrm{aB}$ & $0,53 \mathrm{aB}$ \\
\hline & $2,5-5,0$ & $93,6 \mathrm{aB}$ & $6,4 \mathrm{aA}$ & $71,0 \mathrm{bB}$ & $29,0 \mathrm{aA}$ & $2,78 \mathrm{aB}$ & $1,38 \mathrm{aB}$ & $0,50 \mathrm{aB}$ \\
\hline & $5,0-10,0$ & $94,0 \mathrm{aB}$ & $6,0 \mathrm{aA}$ & $70,8 \mathrm{~b} \mathrm{C}$ & $29,2 \mathrm{aA}$ & $3,03 \mathrm{aB}$ & $1,40 \mathrm{aB}$ & $0,46 \mathrm{aB}$ \\
\hline & $10,0-20,0$ & $94,0 \mathrm{aB}$ & $6,0 \mathrm{aA}$ & $68,3 \mathrm{~b} \mathrm{C}$ & $31,7 \mathrm{aA}$ & $3,08 \mathrm{aB}$ & $1,44 \mathrm{aB}$ & $0,47 \mathrm{aB}$ \\
\hline \multirow{4}{*}{ Pasto } & $0,0-2,5$ & $93,9 \mathrm{bB}$ & 6,1 a A & $75,6 \mathrm{aB}$ & $24,4 \mathrm{aA}$ & $2,64 \mathrm{aB}$ & $1,37 \mathrm{aB}$ & $0,52 \mathrm{aB}$ \\
\hline & $2,5-5,0$ & $95,1 \mathrm{abB}$ & $4,9 \mathrm{abA}$ & $75,7 \mathrm{aB}$ & $24,3 \mathrm{aA}$ & $2,82 \mathrm{aB}$ & $1,61 \mathrm{aB}$ & $0,57 \mathrm{aB}$ \\
\hline & $5,0-10,0$ & $95,4 \mathrm{abB}$ & $4,6 \mathrm{abA}$ & $76,9 \mathrm{aB}$ & 23,1 a B & $2,92 \mathrm{aB}$ & $1,68 \mathrm{aB}$ & $0,58 \mathrm{aB}$ \\
\hline & $10,0-20,0$ & $96,2 \mathrm{aAB}$ & 3,8 a $\mathrm{AB}$ & $75,2 \mathrm{aB}$ & 24,8 a B & $3,19 \mathrm{aB}$ & $1,66 \mathrm{aB}$ & $0,52 \mathrm{aB}$ \\
\hline
\end{tabular}

Letras minúsculas iguais em cada área na coluna e maiúsculas entre as áreas, nas respectivas profundidades, não diferem estatisticamente em nível de 5\% de probabilidade pelo teste de Tukey. 
cana-de-açúcar por décadas nessa área. Apenas no pasto os Macro-s sofrem alterações significativas em profundidade. $\mathrm{O}$ efeito compressivo do pisoteio animal possivelmente aumentou a aproximação das partículas. Essa consolidação natural é denominada de efeito do empacotamento da estrutura (VEZZANI \& MIELNICZUK, 2011).

Para os Micro-s, o resultado se inverte e as áreas sob sabiá e pasto proporcionam os maiores valores. Segundo SOUZA (2010), o pisoteio animal, processos erosivos intensificados e redução do teor de matéria orgânica resultam no fracionamento dos agregados do solo em classes de menor diâmetro. Por isso, os Micro-s aumentaram $267 \%$ e $215 \%$ nas áreas sob sabiá e pasto, respectivamente, em relação à mata.

Quando os Macro-s são submetidos à peneiragem úmida (Macro-u), há uma diminuição aproximada de $24 \%, 20 \%$ e $1,6 \%$ em suas quantidades para as áreas de sabiá, pasto e mata, respectivamente. Os Macro-u são significativamente maiores na área de mata, em todas as profundidades, provavelmente, devido ao maior teor de Argila, MOS e HUM (Tabela 1), ausência de revolvimento do solo e do pisoteio animal existentes nas outras áreas. FONTANA et al. (2010) observaram que a HUM teve efeitos positivos na agregação de um Argissolo em área de mata. A área sob sabiá apresenta os menores valores de Macro-u nas duas últimas profundidades. Possivelmente, o revolvimento do solo, para implantação das mudas de sabiá, tenha contribuído para esse resultado.

Aárea de sabiá apresenta os maiores valores de Micro-u. Por ter sido anteriormente área de pasto e ter sofrido revolvimento do solo, para implantar a cultura do sabiá, a estrutura foi, provavelmente, muito danificada, resultando na perda de estabilidade dos macroagregados $(>0,25 \mathrm{~mm})$, que se desfazem em microagregados $(<0,25 \mathrm{~mm})$. Para VEZZANI \& MIELNICZUK (2011), PEREIRA et al., (2011), PORTUGAL et al., (2010) e SOUZA (2010), o pisoteio animal e o revolvimento do solo promovem a quebra mecânica dos agregados e a redução da matéria orgânica, resultando na produção de microagregados.

O diâmetro médio ponderado de agregados secos (DMPA-s) e úmidos (DMPA-u) e o índice de estabilidade de agregados (IEA) são sempre maiores na área de mata, em todas as profundidades, provavelmente, devido aos maiores teores de Argila, MOS, HUM e ausência de revolvimento e pisoteio animal, levando o IEA próximo da unidade $(0,98)$. Segundo SILVA \& MIELNICZUK (1997), quanto mais próximo de 1,0, maior a estabilidade dos agregados em água. Pesquisas confirmam que maiores teores de HUM contribuem com a agregação, devido à formação de ligações mais estáveis com a fração mineral do solo, promovendo a estabilidade de agregados (FONTANA et al., 2010; LOSS et al., 2006; PORTUGAL et al., 2010). O sabiá apresenta IEA médio de 0,492 e o pasto de 0,550, que estão bem distantes do valor referência $(1,00)$. PIGNATARO NETTO et al. (2009) informam que reduções no IEA ocorrem devido ao pisoteio animal, pouca cobertura do solo e reduções no teor de MOS. O manejo do solo no Brejo Paraibano é preocupante, pois a substituição da vegetação nativa, em declividade elevada, traz perda de argila e MOS, e pode, com o passar do tempo, tornar a exploração agropecuária inviável economicamente, visto que a substituição da vegetação nativa por pastagem e da pastagem pelo plantio de sabiá promove a degradação da estrutura do solo (SANTOS et al., 2010; SOUZA, 2010).

O DMPA-u é significativamente menor na camada superficial, na área de mata. Isto ocorre, provavelmente, pelos maiores teores de areia na superfície. SANTOS et al. (2011) e VEZZANI \& MIELNICZUK (2011) observaram que a predominância de areia promovem uma fragilidade natural na formação e estabilização de agregados. Como o DMPA-u é bem inferior nas outras áreas, a redução de areia entre as camadas não foi suficiente para promover diferenças.

A análise de correlação ente as frações AF, AH e HUM com a estabilização de agregados indica forte influência das frações da MOS na estrutura do solo (Tabela 3). Os Macro-s e Macro-u do solo apresentam correlação positiva, indicando que quanto maiores os teores de $\mathrm{C}$ nas frações $\mathrm{AF}$, AH e HUM, maiores os valores de macroagregados. Por outro lado, os microagregados apresentam correlação negativa, ou seja, quanto maiores os teores de C nas frações AF, AH e HUM, menores os seus valores.

As correlações entre DMPA-s, DMPA-u e IEA com a MOS nas frações AF, AH e HUM foram significativas. Os resultados mostram a importância da MOS na formação e estabilização de agregados no solo. FONTANA et al. (2010) observaram, independentemente dos solos e da profundidade, correlação significativa e positiva do DMPA com a MOS na fração AH em Latossolo. Em Argissolo, observaram correlação significativa entre DMPA e a MOS na fração HUM. Segundo PORTUGAL et al. (2010), esses resultados demonstram a importância das substâncias húmicas (AF, AH e HUM) na agregação do solo.

Dentre as frações da MOS, a HUM foi a que apresentou melhor correlação com o DMPA-s, DMPA-u e IEA. Este resultado concorda com 
Tabela 3 - Análise de correlação entre as frações AF, AH e HUM e Macro e microagregados secos (Macro-s e Micro-s) e úmidos (Macro-u e Micro-u), diâmetro médio ponderado de agregados secos (DMPA-s) e úmidos (DMPA-u) e o índice de estabilidade de agregados (IEA), em um Argissolo Vermelho-Amarelo.

\begin{tabular}{|c|c|c|c|c|c|c|c|}
\hline Fração & Macro-s & Micro-s & Macro-u & Micro-u & DMPA-s & DMPA-u & IEA \\
\hline $\mathrm{AF}$ & $0,48 * *$ & $-0,48 * *$ & $0,47 * *$ & $-0,47 * *$ & $0,24 *$ & $0,36^{* *}$ & $0,46^{* *}$ \\
\hline $\mathrm{AH}$ & $0,41 * *$ & $-0,41 * *$ & $0,59 * *$ & $-0,59 * *$ & $0,60 * *$ & $0,61^{* *}$ & $0,58 * *$ \\
\hline HUM & $0,70^{* * *}$ & $-0,70 * *$ & $0,90^{* *}$ & $-0,89 * *$ & $0,76^{* *}$ & $0,86^{* *}$ & $0,89 * *$ \\
\hline
\end{tabular}

* Significativo a $5 \%$ de probabilidade; ** significativo a $1 \%$ de probabilidade.

FONTANA et al. (2010), que observaram a correlação da HUM com a agregação, quando concluíram que a HUM revelou-se melhor agente agregador em um Argissolo Amarelo. Entretanto, PORTUGAL et al. (2010) observaram que o AH apresentou melhores correlações que a HUM em um Argissolo VermelhoAmarelo.

\section{CONCLUSÃO}

A substituição da vegetação nativa por pastagem promoveu reduções nas quantidades de argila, MOS, HUM, MACRO-s, MACRO-u, DMPA-s, DMPA-u e IEA, em todas as profundidades. A substituição da pastagem por sabiá resultou em menores quantidades de MACRO-u nas duas últimas profundidades. Essa forma de manejo em áreas de elevada declividade, na microrregião do brejo paraibano, promove a degradação física e da matéria orgânica do solo, com reflexos significativos na estabilidade de agregados e nos teores de C na FAH e HUM.

\section{REFERÊNCIAS}

BENITES, V. M. et al. Extração e fracionamento quantitativo de substâncias húmicas do solo: um procedimento simplificado e de baixo custo. Rio de Janeiro: Embrapa, 2003. 7 p. (Comunicado Técnico). Disponível em: <http://www.infoteca.cnptia.embrapa.br/ handle/doc/337076>. Acesso em 12 jan. 2012.

BRASIL. Ministério da Agricultura. Escritório de Pesquisas e Experimentação. Equipe de Pedologia e Fertilidade do Solo. I. Levantamento exploratório-reconhecimento de solos do Estado da Paraíba. II. Interpretação para uso agrícola dos solos do Estado da Paraíba. Rio de Janeiro, 1972. 683p. (Boletim Técnico, 15; SUDENE. Série Pedologia, 8).

CARPENEDO, V.; MIELNICZUK, J. Estado de agregação e qualidade de agregados de latossolos roxos, submetidos a diferentes sistemas de manejo. R Bras Ci Solo, v.14, p.99-105, 1990.

DOBBSS, L. B. et al. Caracterização química e espectroscópica de ácidos húmicos e fúlvicos isolados da camada superficial de Latossolos brasileiros. R Bras Ci Solo, v.33, p.51-63, 2009. Disponível em: <http://www.scielo.br/scielo.php?script=sci_artte
xt\&pid=S0100-06832009000100006>. Acesso em: 12 jan. 2012. doi:10.1590/S0100-06832009000100006.

EMPRESA BRASILEIRA DE PESQUISA AGROPECUÁRIA (EMBRAPA). Centro Nacional de Pesquisa de Solo (Rio de Janeiro, RJ). Sistema Brasileiro de Classificação de Solos. Brasília, 2006. 306p.

EMPRESA BRASILEIRA DE PESQUISA AGROPECUÁRIA (EMBRAPA). Centro Nacional de Pesquisa de solos. Manual de métodos de análises de solo. Rio de Janeiro, 1997. 212p.

FERREIRA, R. L. C. et al. Deposição e acúmulo de matéria seca e nutrientes em serapilheira em um bosque de sabiá (Mimosa caesalpiniifolia Benth.). R Árvore, v.31, p.7-12, 2007. Disponível em: <http://www.scielo.br/scielo.php?script=sci_arttext\&pid $=$ S0100-67622007000100002>. Acesso em 22 maio, 2013. doi: 10.1590/S0100-67622007000100002.

FONTANA, A. et al. Índices de agregação e a relação com as substâncias húmicas em Latossolos e Argissolos de tabuleiros costeiros, Campos dos Goytacazes, RJ. Rev Bras Ciênc Agrárias, v.5, p.291-297, 2010. Disponível em: <http://redalyc.uaemex.mx/ redalyc/ pdf/1190/119016971002.pdf>. Acesso em: 12 jan. 2012. doi: 10.5239/agrariav5i3a461.

LOSS, A. et al. Distribuição das substâncias húmicas em solos de tabuleiros sob diferentes coberturas vegetais. Rev Univ Rural, Sér Ci da Vida, v.26, p.68-77, 2006. Disponível em: <http://www. editora.ufrrj.br/rcv2/vida26-2/68-77.pdf>. Acesso em:12 jan. 2012.

PEREIRA, F. de S. et al. Qualidade física de um Latossolo Vermelho submetido a sistemas de manejo avaliado pelo índice S. R Bras Ci Solo, v.35, p.87-95, 2011. Disponível em: <http:// www.scielo.br/scielo.php?pid=S0100-06832009000300020\& script=sciarttext $>$. Acesso em: 12 jan. 2012. doi: 10.1590/S010006832009000300020 .

PIGNATARO NETTO, I. T. et al. Atributos físicos e químicos de um Latossolo Vermelho-Amarelo sob pastagens com diferentes históricos de uso. R Bras Ci Solo, v.33, p.1441-1448, 2009. Disponível em: <http://www.scielo.br/pdf/rbcs/v33n5/v33n5a34.pdf>. Acesso em: 12 jan. 2012. doi: 10.1590/S0100-06832009000500034.

PORTUGAL, A. F. et al. Estabilidade de agregados em Argissolo sob diferentes usos, comparado com mata. Rev Ceres, v.57, p.545553, 2010. Disponível em: <http://www.ceres.ufv.br/ceres/revistas/ V57N004P14008.pdf>. Acesso em: 12 jan. 2012.

PORTUGAL, A. F. et al. Determinação de estoques totais de carbono e nitrogênio e suas frações em sistemas agrícolas 
implantados em Argissolo Vermelho-Amarelo. R Bras Ci Solo, v.32, p.2091-2100, 2008. Disponível em: <http://www.scielo.br/ scielo.php?pid=S0100-06832008000500030\&script=sci_arttext $>$. Acesso em: 12 jan. 2012. doi: 10.1590/S0100-06832008000500030

PULROLNIK, K.; BARROS, N. F. et al. Estoques de carbono e nitrogênio em frações lábeis e estáveis da matéria orgânica de solos sob eucalipto, pastagem e cerrado no Vale do Jequitinhonha-MG. R Bras Ci Solo, v.33, p.1125-1136, 2009. Disponível em: <http://www.scielo. br/scielo.php?script=sci_arttext\&pid=S0100-06832009000500006>. Acesso em:13 jan. 2012. doi: 10.1590/S0100-06832009000500006.

SANTOS, D. C. dos. et al. Agregação e frações físicas da matéria orgânica de um Argissolo Vermelho sob sistemas de uso no bioma Pampa. R Bras Ci Solo, v.35, p.1735-1744, 2011 Disponível em: <http://www.scielo.br/scielo.php?pid=S0100$06832011000500028 \&$ script $=$ Sci_arttext $>$. doi: $10.1590 / \mathrm{S} 0100$ 06832011000500028 .

SANTOS, J. T. et al. Atributos físicos e químicos do solo de Áreas sob Pastejo na Micro Região do Brejo Paraibano. Ciênc Rural, v.40, p.2486-2492, 2010. Disponível em: <http://www.scielo.br/ scielo.php?script=sci_arttext $\&$ pid=S0103-84782010001200008>. Acessoem: 13 jan. 2012. doi: 10.1590/S0103-84782010001200008.

SILVA, I. F.; MIELNICZUK, J. Ação do sistema radicular de plantas na formação e estabilização de agregados do solo. R Bras Ci Solo, v.21, p.113-117, 1997.

SOUZA, J. M. de. Dinâmica de atributos físicos e químicos de um Argissolo Vermelho Amarelo em topossequência de pastagem cultivada no brejo paraibano. (Mestrado em Manejo do Solo) - Universidade Federal da Paraíba, Areia, PB.

TISDALL, J. M. et al. The stability of soil agregates as affected by organic materials microbial activity and physical dsireption. Aust J Soil res, v.16, p.9-17, 1978.

VEZZANI, F. M. \& MIELNICZUK, J. Agregação e estoque de carbono em Argissolo submetido a diferentes práticas de manejo agrícola. R Bras Ci Solo, v.35, p.213-223, 2011. Disponível em: <http://www.scielo.br/scielo.php?pid=S010006832011000100020\&script $=$ sci_arttext $>$. Acesso em:13 jan. 2012. doi: 10.1590/S0100-06832011000100020. 